\title{
Effects of long-term progesterone on developmental and functional aspects of porcine uterine epithelia and vasculature: progesterone alone does not support development of uterine glands comparable to that of pregnancy
}

\author{
Daniel W Bailey ${ }^{1}$, Kathrin A Dunlap ${ }^{1}$, James W Frank ${ }^{1}$, David W Erikson ${ }^{1}$, Bryan G White ${ }^{1}$, \\ Fuller W Bazer ${ }^{2}$, Robert C Burghardt ${ }^{1}$ and Greg A Johnson ${ }^{1}$ \\ Departments of ${ }^{1}$ Veterinary Integrative Biosciences and ${ }^{2}$ Animal Science, Texas A\&M University, College Station, \\ Texas 77843-4458, USA
}

Correspondence should be addressed to G A Johnson; Email: gjohnson@cvm.tamu.edu

\begin{abstract}
In pigs, endometrial functions are regulated primarily by progesterone and placental factors including estrogen. Progesterone levels are high throughout pregnancy to stimulate and maintain secretion of histotroph from uterine epithelia necessary for growth, implantation, placentation, and development of the conceptus (embryo and its extra-embryonic membranes). This study determined effects of longterm progesterone on development and histoarchitecture of endometrial luminal epithelium (LE), glandular epithelium (GE), and vasculature in pigs. Pigs were ovariectomized during diestrus (day 12), and then received daily injections of either corn oil or progesterone for 28 days. Prolonged progesterone treatment resulted in increased weight and length of the uterine horns, and thickness of the endometrium and myometrium. Hyperplasia and hypertrophy of GE were not evident, but LE cell height increased, suggesting elevated secretory activity. Although GE development was deficient, progesterone supported increased endometrial angiogenesis comparable to that of pregnancy. Progesterone also supported alterations to the apical and basolateral domains of LE and GE. Dolichos biflorus agglutinin lectin binding and $\alpha_{v}$ integrin were downregulated at the apical surfaces of LE and GE. Claudin-4, $\alpha_{2} \beta_{1}$ integrin, and vimentin were increased at basolateral surfaces, whereas occludins-1 and -2, claudin-3, and E-cadherin were unaffected by progesterone treatment indicating structurally competent trans-epithelial adhesion and tight junctional complexes. Collectively, the results suggest that progesterone affects LE, GE, and vascular development and histoarchitecture, but in the absence of ovarian or placental factors, it does not support development of GE comparable to pregnancy. Furthermore, LE and vascular development are highly responsive to the effects of progesterone.
\end{abstract}

Reproduction (2010) 140 583-594

\section{Introduction}

Progesterone profoundly influences successful pregnancy. Administration of exogenous progesterone to recipient cows early in the estrous cycle advances uterine functions and receptivity for transfer of older asynchronous embryos (Geisert et al. 1991), and advances conceptus development in both sheep and cattle when administered early, i.e. within 3 days after mating (Satterfield et al. 2006, Carter et al. 2008). Indeed, treatment with exogenous progesterone significantly alters the expression of a number of genes in rodent, primate, and sheep uteri (Ace \& Okulicz 2004, Jeong et al. 2005, Gray et al. 2006). Although similar gene expression studies have not been performed in pigs, progesterone increases the expression of calbindin-D9k (Yun et al. 2004), vascular endothelial growth factor
(Welter et al. 2004), fibroblast growth factors (FGFs) 2 and 7 , two FGF receptors, FGFR1 and FGFR2 (Welter et al. 2003, Ka etal. 2007), $\alpha_{4}, \alpha_{5}$, and $\beta_{1}$ integrin receptor subunits (Bowen et al. 1996), the swine leukocyte antigens 1, 2, and 3, and $\beta(2)$-microglobulin (Joyce et al. 2008), as well as suppresses expression of MUC1 and progesterone receptor in luminal epithelium (LE; Geisert et al. 1994, Bowen et al. 1996). Importantly, progesterone increases the expression of various uterine secretory proteins that are components of the histotroph, which is hypothesized to support conceptus and fetal development in pigs (Knight et al. 1974a, 1974b, Roberts \& Bazer 1988).

All mammalian uteri contain endometrial epithelia, both glandular (GE) and LE, that secrete 'histotroph', a complex mixture of hormones, enzymes, growth factors, cytokines, transport proteins, adhesion factors, 
nutrients, and other substances that play roles in conceptus nourishment, implantation, and placentation of the conceptus (embryo and associated placental membranes; Roberts \& Bazer 1988, Gray et al. 2001, Hempstock et al. 2004). Uterine secretions are particularly important for pregnancy success in pigs, sheep, cattle, and horses, which exhibit 1) a prolonged period in which free-floating conceptuses elongate, and 2) superficial placentation that results in a multilayered tissue barrier to the transport of substances from maternal uterine blood vessels to blood vessels of the conceptus. The majority of histotroph is thought to be secreted by the endometrial GE, and it is accepted that progesterone is the primary hormone that transforms the pregnant endometrium into a secretory tissue to support early embryonic development, implantation, placentation, and fetal/placental development (Spencer et al. 2004).

Little is actually known about the hormonal regulation of the structural changes that occur within LE and GE as they develop into a mature secretory phenotype. Multiple studies suggest that histotroph production increases primarily in response to ovarian progesterone during pregnancy in the pig (Knight et al. 1974a, 1974b, Schlosnagle et al. 1974, Basha et al. 1980, Geisert et al. $1982 a, 1982 b)$, and that progesterone alone is sufficient to support pregnancy levels of histotroph (Schlosnagle et al. 1974, Basha et al. 1980). However, results for uteroferrin, a well-known progesterone-induced component of histotroph, suggest that interactions among progesterone, lactogenic hormones, and ovarian steroids may constitute a 'servomechanism' regulating endometrial remodeling, secretory function, and uterine growth in pigs (Young et al. 1990). Therefore, there is discrepancy in the scientific literature pertaining to progesterone's relative contribution to the endometrial epithelial development that underlies the synthesis and secretion of histotroph during pregnancy.

We hypothesized that progesterone alone supports the development of porcine uterine glands comparable to that of pregnancy. However, the histomorphology of uterine GE and structural modifications to endometrium, including vasculature, for increased secretory activity have never been examined in ovariectomized gilts given exogenous progesterone through the critical window of days 30-40 when ultrastructural adaptations of uterine epithelia for secretion have been noted in pigs (Perry \& Crombie 1982, Sinowatz \& Friess 1983). Therefore, in order to address the role progesterone serves to modulate molecular factors within the endometrium, impacting placental function and pregnancy maintenance in the absence of confounding factors due to the presence of the ovary and conceptuses, gilts were ovariectomized on day 12 of the estrous cycle and treated daily with progesterone for 28 days to assess the effects of long-term progesterone on the morphology and expression of selected structural proteins by porcine uterine LE and GE in the absence of conceptus and/or ovarian factors.
Results suggest that 1) progesterone alone does not support the development of GE comparable to that of pregnancy, and that 2) LE and vasculature are equally or more responsive to the effects of progesterone than GE.

\section{Results}

The gross anatomy of uteri differed between ovariectomized gilts treated with corn oil (CO) or progesterone. Uteri from CO-treated gilts were reduced both in length and diameter relative to their progesterone-treated counterparts, and the endometrial thickness was also reduced. In addition, the endometrial and myometrial tissues were blanched in the uteri from the CO treatment compared with uteri from progesterone-treated gilts (Fig. 1).

Histological examination of uterine epithelia and endothelium revealed measurable differences in LE, but not in GE, between gilts treated with $\mathrm{CO}$ or progesterone. The LE cells of endometria from progesterone-treated gilts were significantly taller than LE cells from CO-treated gilts (Fig. 2). These LE cells exhibited secretory
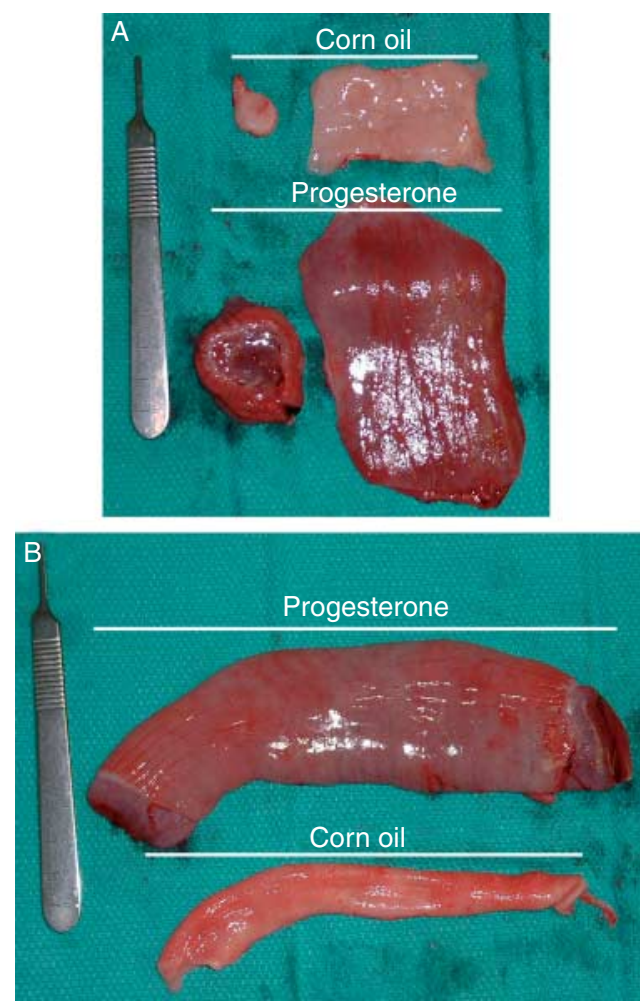

Figure 1 Gross anatomical effects of progesterone on uteri of ovariectomized pigs. Uteri from corn oil- and progesterone-treated gilts were photographed immediately after hysterectomy on day 40 . (A) Cross sections through the entire uterine horns are shown. The sections on the left side of the panel are complete cross sections with myometrium on the outer rim of the circular organ and endometrium in the interior. The right section has been opened along the mesometrial border to show the luminal surface of the endometrium.

(B) Longitudinal sections of the entire uterine horn are shown. 

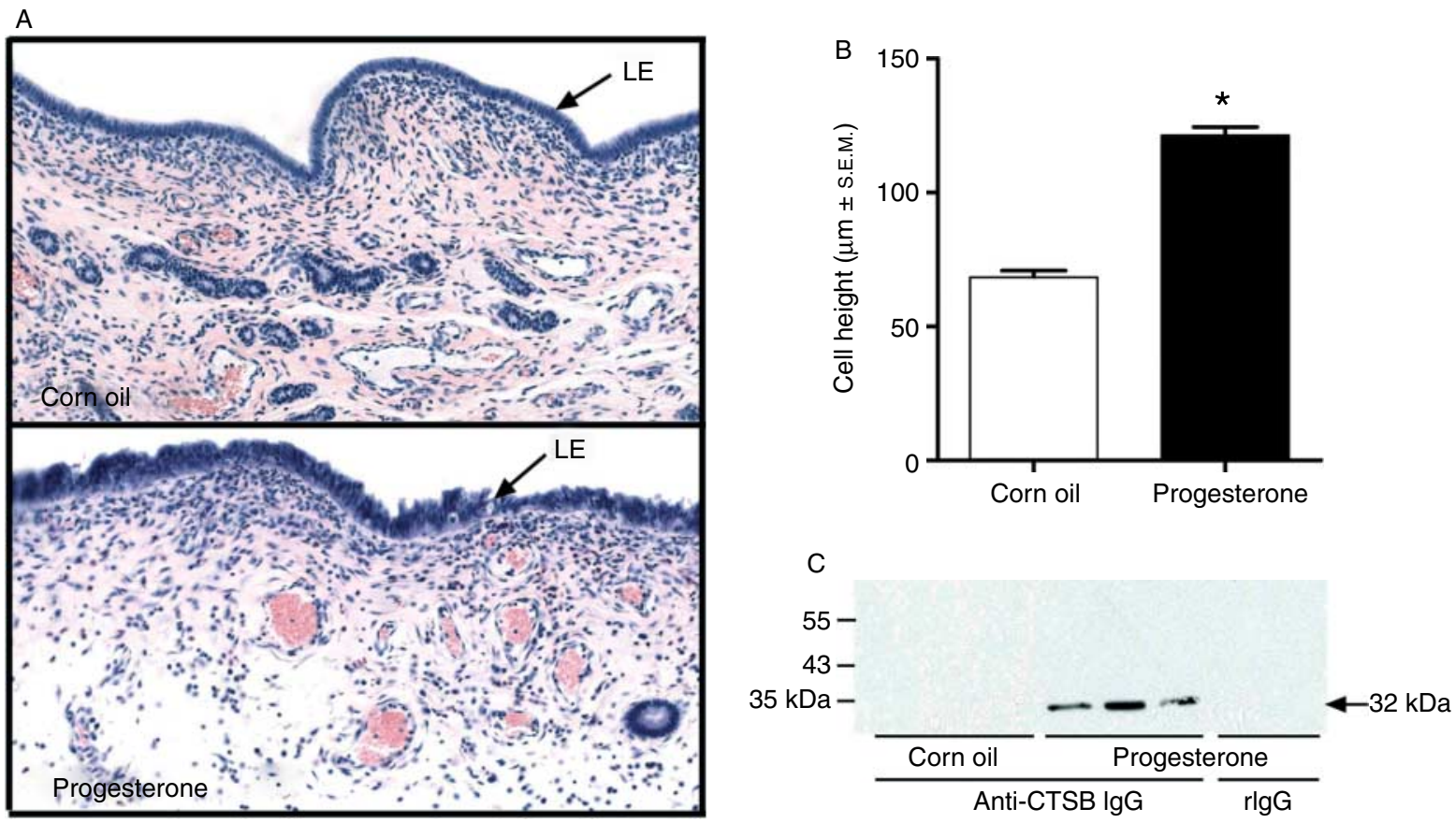

Figure 2 Effects of progesterone on the histology and secretory activity of pig uterine LE. (A) Representative photomicrographs of hematoxylin and eosin-stained uterine cross sections from corn oil- and progesterone-treated ovariectomized gilts on day 40 are shown. The images focus on the uterine luminal epithelium (LE). Width of each field is $870 \mu \mathrm{m}$. Note the increased LE height in progesterone- as compared with corn oil-treated gilts. (B) Quantification of LE cell height is shown. The height of LE was increased in progesterone-treated gilts over corn oil-treated gilts $\left({ }^{*} P<0.05\right)$. (C) Western blot analysis (under reducing conditions) of uterine secretions from corn oil- and progesterone-treated pigs. Normal rabbit IgG was substituted for primary antibody as the control and can be observed in Fig. 3C. A CTSB protein of $\sim 32 \mathrm{kDa}$ was detected in uterine secretions from progesterone-treated pigs only.

function because immunoreactive cathepsin B (CTSB), a protease expressed and secreted from the LE of pregnant pigs (Song et al. 2010), was detected in the uterine flushings of progesterone-treated pigs (Fig. 2C). In contrast, there were no differences in the size, density, or distribution of endometrial glands between progesterone- and CO-treated gilts in regions of the endometrium near the LE, and total gland number was decreased in regions of the endometrium near the myometrium in progesterone-treated pigs compared with CO-treated pigs (Fig. 3). Therefore, adenogenesis did not increase enough in response to progesterone to maintain GE density in the deep endometrium of growing uteri. However, the GE of progesterone-treated gilts exhibited secretory function because immunoreactive acid phosphatase 5, tartrate resistant (ACP5, commonly referred to as uteroferrin) proteins of $\sim 37-38 \mathrm{kDa}$ were detected in the uterine flushings of progesteronetreated pigs (Fig. 3C). Although long-term treatment with progesterone did not support GE development comparable to that of pregnancy, treatment of ovariectomized pigs with progesterone alone increased total endometrial angiogenesis. The density and distribution of endothelium were not different between $\mathrm{CO}$ - and progesterone-treated pigs in shallow endometrium. However, total endothelium was significantly increased by progesterone in deep endometrium, indicating increased angiogenesis in growing uteri (Fig. 4).

In order to examine alterations in the apical domain of endometrial epithelia in ovariectomized gilts in response to progesterone treatment, uteri were stained for Dolichos biflorus agglutinin (DBA) lectin and $\alpha_{v}$ integrin subunit, a major integrin present at the apical surface of uterine LE (Erikson et al. 2009; Fig. 5). DBA lectin was prominent at the apical surface of both LE and GE of CO-treated gilts. In contrast, progesterone treatment resulted in complete loss of DBA lectin in $L E$, and only low levels of DBA lectin staining were maintained in GE (Fig. 5A). A similar but less extensive alteration in $\alpha_{v}$ integrin subunit expression was observed in pig endometrial epithelia (Fig. 5B). Immunostaining intensity for $\alpha_{v}$ integrin subunit appeared to be greater within the apical domain of LE and GE of CO-treated gilts compared with progesterone-treated gilts (Fig. 5B).

In order to examine the integrity of tight junctional complexes of endometrial epithelia in ovariectomized gilts in response to progesterone treatment, the organization of zona occludins (ZOs)- 1 and -2 , as well as claudins- 3 and -4 was evaluated by immunofluorescence staining (Fig. 6). The occludin proteins were 

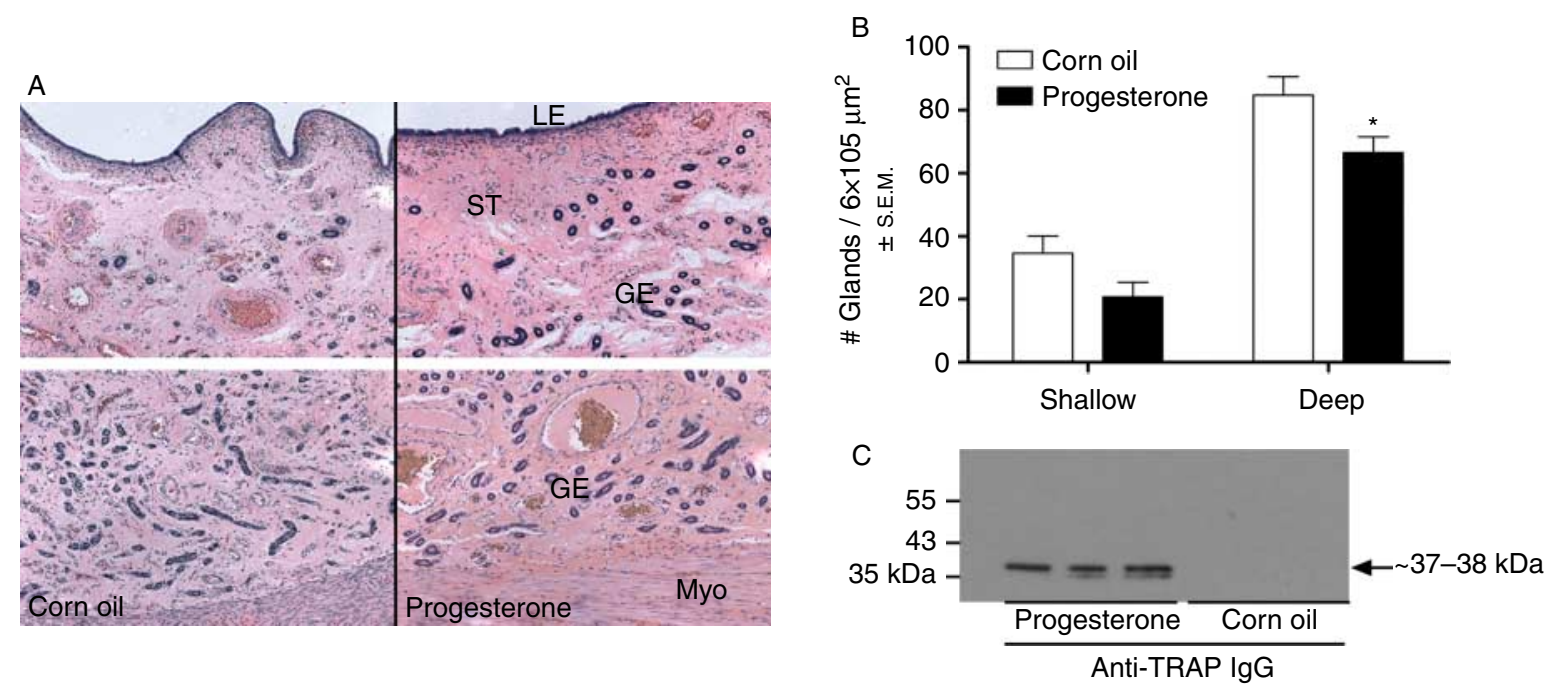

Figure 3 Effects of progesterone on the histology and secretory activity of pig uterine GE. (A) Representative photomicrographs of hematoxylin and eosin-stained uterine cross sections from corn oil- and progesterone-treated ovariectomized gilts on day 40 are shown. The images focus on the shallow to middle GE (top sections) and the middle to deep GE (bottom sections). Width of each field is $870 \mu \mathrm{m}$. Note that there is no obvious increase in size or number of uterine glands in progesterone-treated gilts as compared with corn oil-treated gilts. (B) Quantification of uterine glands $/ 6 \times 10^{5} \mu \mathrm{m}^{2}$ field is shown; Shallow represents counts of shallow to middle GE, whereas Deep represents counts of middle to deep GE. The number of deep glands per field was decreased in progesterone-treated gilts versus corn oil-treated gilts $\left({ }^{*} P<0.005\right)$. (C) Western blot analysis (under reducing conditions) of uterine secretions from CO- and progesterone-treated pigs. Normal rabbit lgG was substituted for primary antibody as the control and can be observed in (C). Two isoforms of ACP5 protein of $\sim 37$ and $38 \mathrm{kDa}$ were detected in uterine secretions from progesterone-treated pigs only.

localized to the terminal web tight junctional complexes of both LE and GE, and no differences were observed in intensity or distribution of either occludin protein between $\mathrm{CO}-$ and progesterone-treated gilts (Fig. 6). In contrast, a divergence in immunostaining between the claudin proteins was observed. Although claudin-3 was localized to tight junctional complexes of LE and GE in endometria from both $\mathrm{CO}$ - and progesterone-treated gilts, claudin-4 was expressed only in epithelia of progesterone-treated gilts. Interestingly, progesteroneinduced expression of claudin-4 protein was observed along the entire basal and lateral surfaces of both LE and GE in a pattern more representative of E-cadherin than a typical claudin that is normally limited to tight junctions (Fig. 6).

Finally, the basolateral surfaces and the intermediate cytoskeletal filaments of LE, GE, and stromal fibroblasts were examined by immunofluorescence staining for E-cadherin, $\alpha_{2} \beta_{1}$ integrin heterodimer, cytokeratin, and vimentin (Fig. 7). E-cadherin was localized along the entire basal and lateral surfaces of LE and GE in the endometria of both CO- and progesterone-treated gilts (Fig. 7) with no discernable differences. In sharp contrast, the $\alpha_{2} \beta_{1}$ integrin heterodimer was absent in CO-treated gilts, and induced by progesterone along both the basal and lateral surfaces of LE and GE (Fig. 7). As expected, the epithelial-specific cytokeratin, an epithelial specific marker, was expressed in all uterine epithelia, and vimentin, a mesenchyme-specific marker, was not expressed in uterine epithelia, but was abundant in uterine stromal cells. An unexpected result of this study was induction of vimentin at the basal and lower third of the lateral surfaces of $L E$, but not $G E$, in response to progesterone treatment (Fig. 7).

\section{Discussion}

Progesterone is the unequivocal hormone of pregnancy; however, its effects on the development, microstructure, and function of uterine epithelia and endothelium of pigs are not understood. Results of previous studies indicated that long-term daily treatment of ovariectomized pigs with progesterone promoted secretory activity of uterine epithelia that was similar to that of pregnancy, whereas treatment of ovariectomized pigs with the proper ratio of progesterone and estrogen enhanced secretion of uteroferrin over progesterone alone (Knight et al. 1973, Schlosnagle et al. 1974, Basha et al. 1980, Young et al. 1990). This present study begins to dissect the effects of progesterone alone on the anatomical and histological properties of GE and LE, which secrete histotroph that is essential to pregnancy in pigs. Results indicate that progesterone has greater effects on the histoarchitecture of LE than GE. These results suggest that, during the first trimester of pregnancy in pigs, LE plays a significant role in synthesis and transport of histotroph. Furthermore, GE development that occurs during the second trimester of pregnancy likely requires sequential exposure of the uterus to a series of hormones and factors that may include progesterone, estradiol, and prolactin in 
a servomechanism similar to that described for sheep and rabbits (Chilton et al. 1988, Spencer et al. 1999), whereas effects of progesterone alone are clearly permissive to or required to drive angiogenesis.
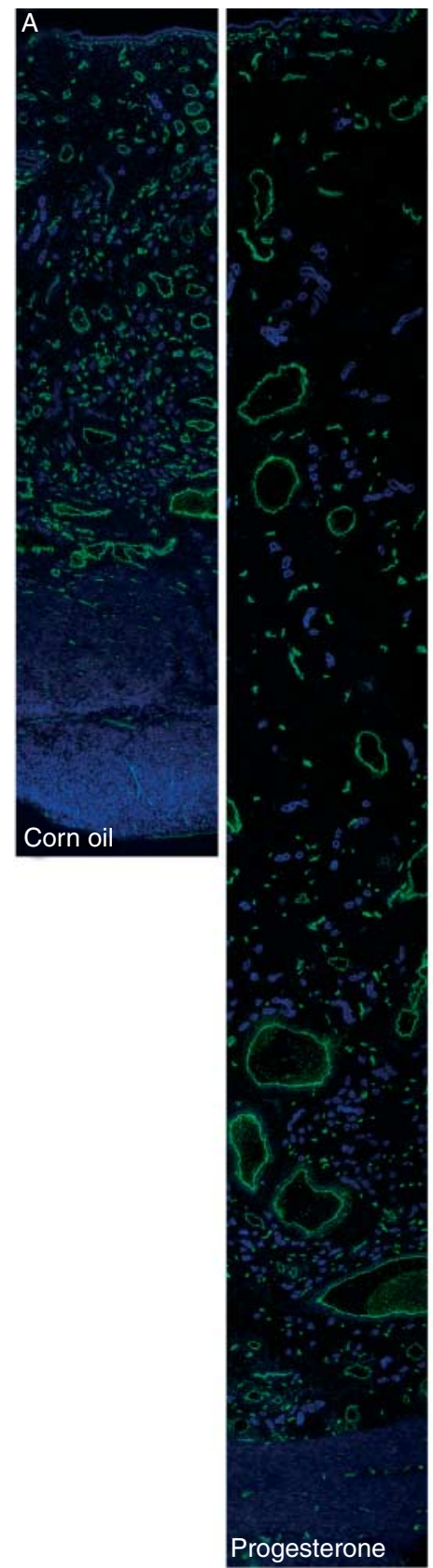

\section{B}

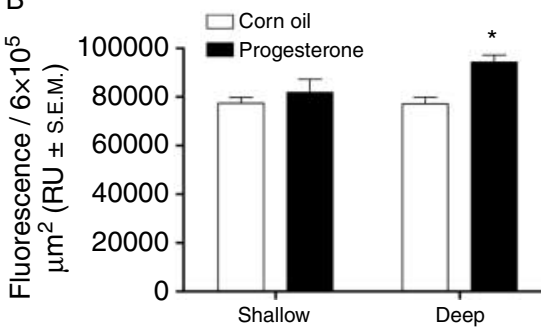

There are few descriptions of the hypertrophy and hyperplasia that the uterine GE of pigs undergo as GE increases production of histotroph, particularly between days 30 and 90 of pregnancy (Knight et al. 1977, Basha et al. 1980, Perry \& Crombie 1982, Sinowatz \& Friess 1983). Endometrial GE development, or adenogenesis, begins during early postnatal life in pigs (Bartol et al. 1993, Gray et al. 2001). A series of elegant studies have implicated estrogen and relaxin as key mediators of early GE development in pigs (Bartol et al. 2006). The GE of nonpregnant adult pigs are lined by a low cuboidal epithelium that shows few adaptations to indicate high secretory activity (Perry \& Crombie 1982). However, the GE of day 17 pregnant pigs, while remaining low cuboidal, have increased rough endoplasmic reticulum and Golgi, suggesting synthesis of secretory products (Perry \& Crombie 1982). The GE remain simple, coiled, and tubular through day 30 of pregnancy, but develop characteristics of increased secretory activity by day 35 when GE cells exhibit extensive rough endoplasmic reticulum with flocculent-filled cysternae. By midpregnancy, the lumens of uterine glands are greatly enlarged and filled with secretory products (Perry \& Crombie 1982, Sinowatz \& Friess 1983). In the present study, there were no differences in the number of uterine glands per unit area of shallow endometrium (near the LE) between ovariectomized gilts treated with either CO or progesterone for 40 days, but adenogensis was clearly unable to keep pace with growth of the uterine wall as GE were decreased in deep endometrium (near the myometrium) of progesterone-treated pigs compared with CO-treated pigs. Although there were more total GE cells in uteri of progesterone-treated gilts than CO-treated gilts, due to increased uterine horn length and endometrial thickness, GE branching and coiling as they extended into the uterine wall were insufficient to maintain GE density. Indeed, GE number and size did not approach levels normally observed on day 40 of pregnancy (Garlow et al. 2002, Song et al. 2009, 2010). This is in contrast to the vasculature of the uterus, which increased in proportion to the thickness of the uterine wall in shallow regions of the endometrium, and significantly increased in density in the deep endometrium of progesterone-treated pigs compared with CO-treated pigs.

Figure 4 Effects of progesterone on uterine vasculature. (A) Representative photomicrographs of immunofluorescence staining for von Willebrand factor (vWF) in frozen uterine cross sections from corn oil- and progesterone-treated ovariectomized gilts on day 40 are shown. Multiple digital images were captured across the uterine wall and assembled in Adobe Photoshop to illustrate vWF staining in the entire endometrium. Width of each field is $870 \mu \mathrm{m}$. (B) Quantification of vWF fluorescence in endothelium $/ 6 \times 10^{5} \mu \mathrm{m}^{2}$ field is shown; Shallow represents $v W F$ staining area in the upper half of the endometrium on the LE side, whereas Deep represents staining area on the lower half of the endometrium on the myometrial side. VWF immunofluorescene per field was increased in progesterone-treated gilts versus corn oil-treated gilts $\left({ }^{*} P<0.05\right)$. 
A DBA lectin
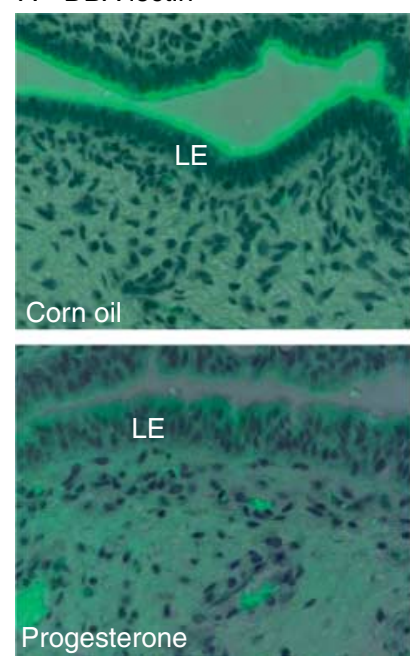
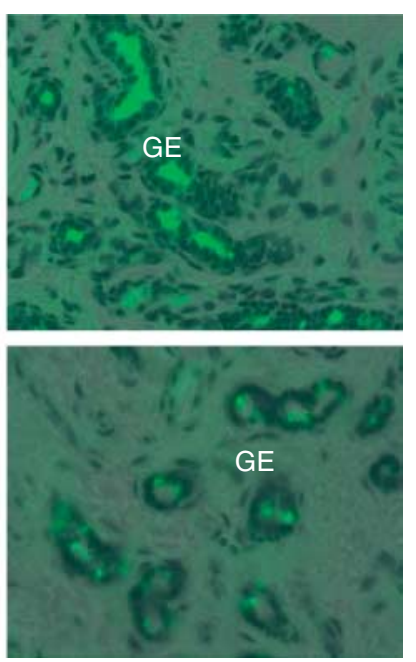

B $\alpha_{v}$ integrin
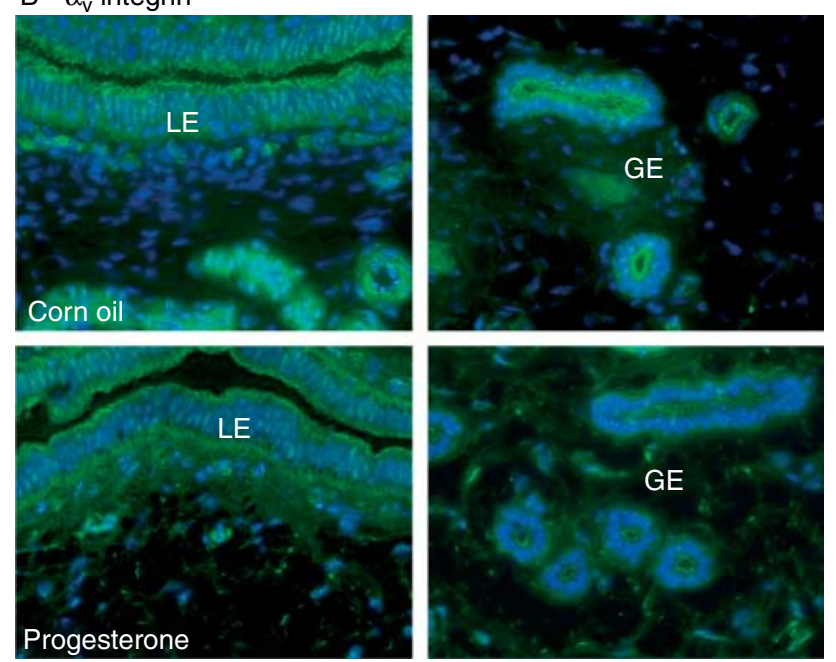

Figure 5 Effects of progesterone on the apical surface of uterine luminal epithelium (LE) and glandular epithelium (GE). (A) Fluorescence of Dolichos biflorus agglutinin (DBA) lectin staining on day 40 endometria from ovariectomized gilts treated with corn oil or progesterone is shown. Sections are counterstained with hematoxylin. (B) Immunofluorescence localization of $\alpha_{v}$ integrin subunit on day 40 endometria from ovariectomized gilts treated with CO or progesterone is shown. The nuclei are stained (blue) with DAPI. Rabbit IgG applied to an endometrial section from a corn oil-treated gilt served as a negative control as shown in Fig. 6. Width of each field is $540 \mu \mathrm{m}$.

A series of studies confirmed that the early pregnant pig uterus begins to secrete moderate levels of histotroph, and that total uterine secretions increase dramatically after day 30 of pregnancy. These studies further suggested that histotroph production increased primarily in response to ovarian progesterone during pregnancy in the pig (Knight et al. 1974a, 1974b, Schlosnagle et al. 1974, Basha et al. 1980, Geisert et al. 1982a, 1982b). Indeed, the idea that progesterone alone, in the absence of ovarian or placental factors, is sufficient to support pregnancy levels of histotroph is supported by data showing that amounts of luminal secretory protein recovered per horn from ovariectomized gilts administered progesterone daily for up to 60 days are comparable to those obtained from pseudopregnant and unilaterally pregnant animals (Schlosnagle et al. 1974, Basha et al. 1980). However, in pigs, similar to rabbits and sheep, interactions between lactogenic hormones and ovarian steroids have been proposed to constitute a 'servomechanism' regulating endometrial remodeling, secretory function, and uterine growth (Chilton et al. 1988, Young et al. 1990, Spencer et al. 1999). For example, uteroferrin is induced in endometrial GE by progesterone, but previous studies suggest that prolactin binding to its endometrial receptors may increase endometrial estrogen receptors that mediate the ability of exogenous estrogen to enhance progesterone-induced uteroferrin secretion in gilts treated daily with progesterone after ovariectomy (Knight et al. 1973, Young et al. 1990). Results of the present study suggest that a servomechanism is responsible for GE development. We hypothesize that progesterone is sufficient to continue GE growth to maintain extension of tubular structures to the myometrial border as the endometrium thickens, but that the hypertrophy and hyperplasia of GE, which occur after day 30 of pregnancy, require the temporal and spatial influence of additional maternal and fetal hormones and/or factors. We propose that excellent candidates for involvement in this servomechanism are placental estrogens, interleukin-1 $\beta$, and interferons $\gamma$ and $\delta$, as well as prolactin and prolactin receptors (Young et al. 1990, Ross et al. 2003, Johnson et al. 2009). In contrast, endometrial angiogenesis is less dependent on a servomechanism, and to a great extent can be supported by the actions of progesterone alone.

In contrast to GE, LE responded to progesterone with a change in epithelial morphology from low cuboidal to tall columnar. As it is typical for epithelial cells lining the lumen of the female reproductive tract to become taller as secretory activity is increased, it is likely that the uterine LE of progesterone-treated pigs is responding to progesterone by increasing the synthesis and secretion of components of histotroph into the uterine lumen (Davies \& Hoffman 1975, Geisert et al. 1982a, 1982b, Verhage et al. 1984, Murray 1992, Brenner \& Slayden 1994). Indeed, the progesterone-responsive protease CTSB, which is expressed in the pig LE, but not GE, increased in the uterine flushings of progesterone-treated gilts, confirming the LE to be functionally secretory. Therefore, a significant percentage of histotroph is derived from the LE during the first trimester of pregnancy in pigs. Recently, several genes hypothesized to have roles during early pregnancy have been localized within pig LE (Johnson et al. 2009). It is reasonable to conclude that progesterone, at least in part, increases the secretory activity of the LE of pregnant pigs and that LE shares 

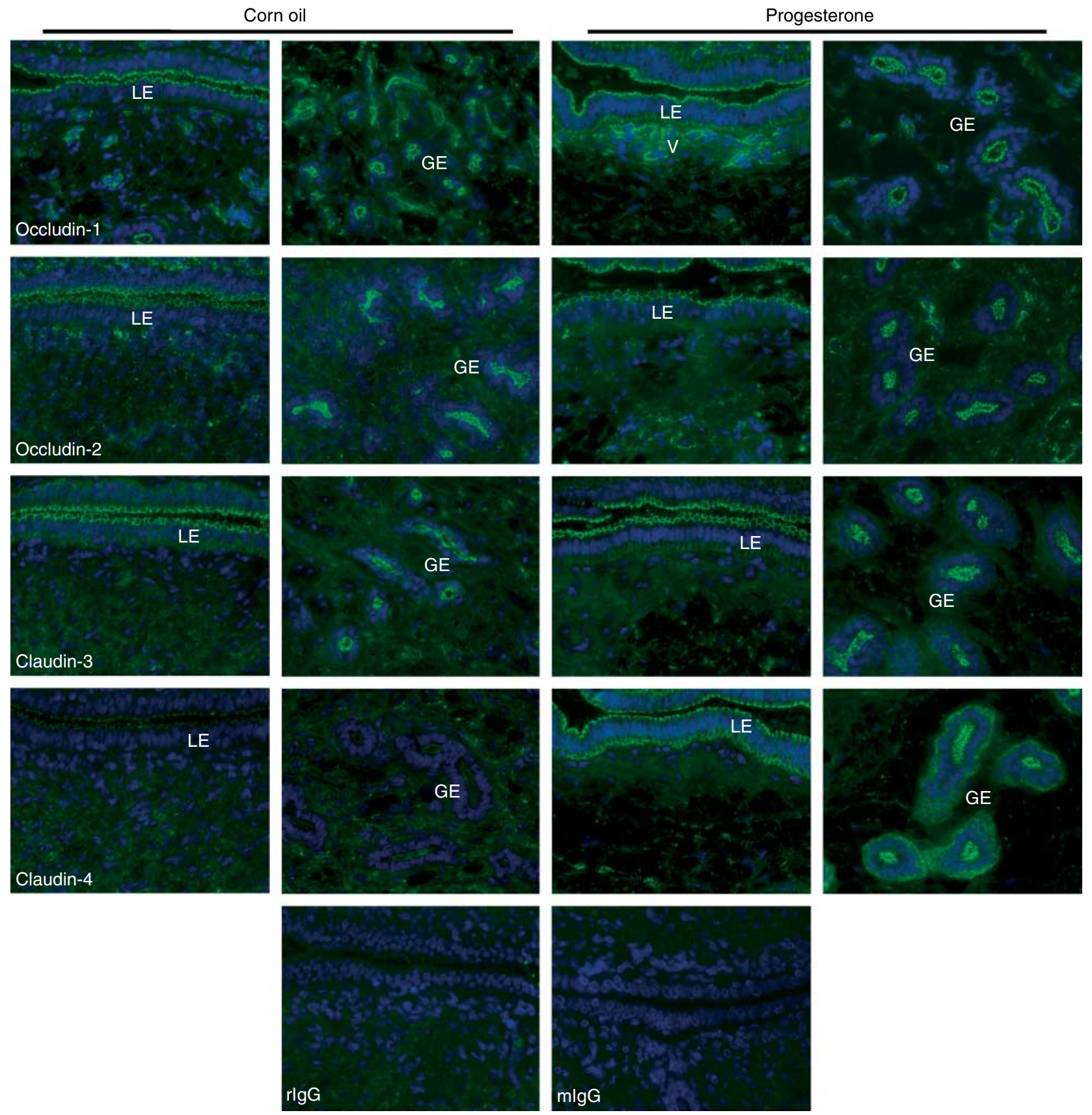

Figure 6 Effects of progesterone on tight junctional complexes of uterine LE and GE. Immunofluorescence localization of zona occludin-1 (occludin-1), zona occludin-2 (occludin-2), claudin-3, and claudin-4 on day 40 endometria from ovariectomized gilts treated with corn oil or progesterone is shown. The nuclei are stained (blue) with DAPI. Rabbit IgG or mouse IgG applied to endometrial sections from corn oil-treated gilts served as negative controls. Width of each field is $540 \mu \mathrm{m}$.

an important role along with the GE in the production of histotroph necessary for pig blastocyst development, elongation, implantation, and placentation of pig conceptuses.

In epithelia, the apical domain interacts with the external environment of the uterine lumen. This surface mediates complex physiological interactions between the uterus and trophectoderm/chorion throughout pregnancy in pigs that have an epitheliochorial placenta.
Many LE secretions are released from vesicles at the apical membrane, while the apical domain also accommodates attachment to the placental epithelium for implantation and placentation. The glycocalyx and integrins are prominent at this surface (Bowen et al. 1996, Sant'Ana et al. 2009). Surface glycoproteins, including galactosamines, and integrins, including $\alpha_{v}$ are important to conceptus attachment in the pig (Dantzer 1985, Geisert et al. 1995, Bowen et al. 1996, 
Corn oil
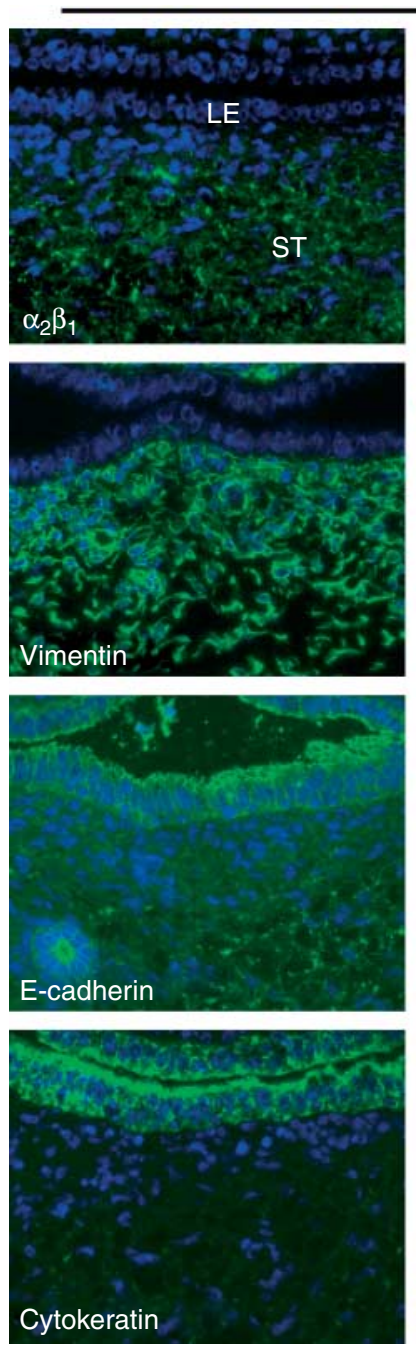
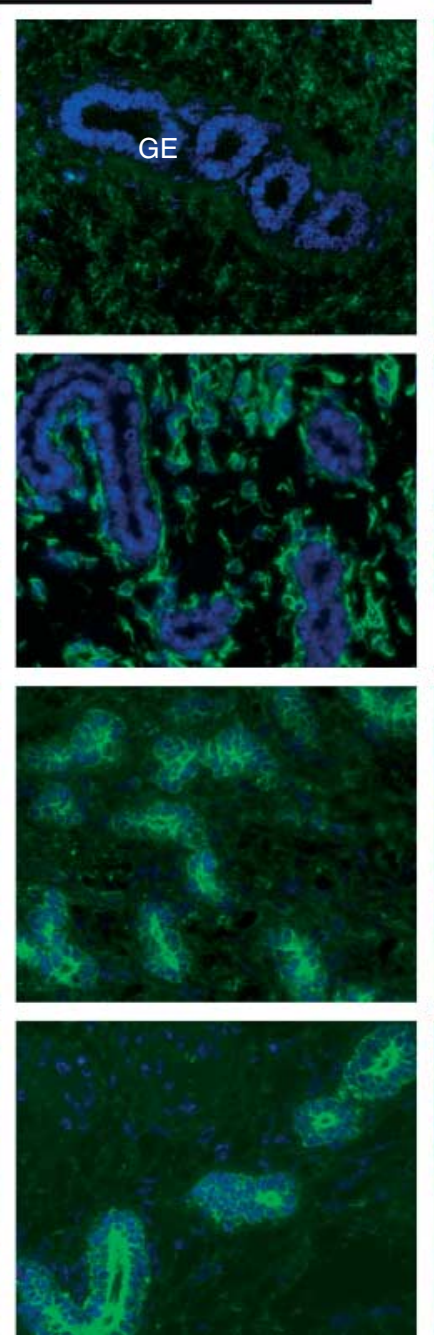

Progesterone
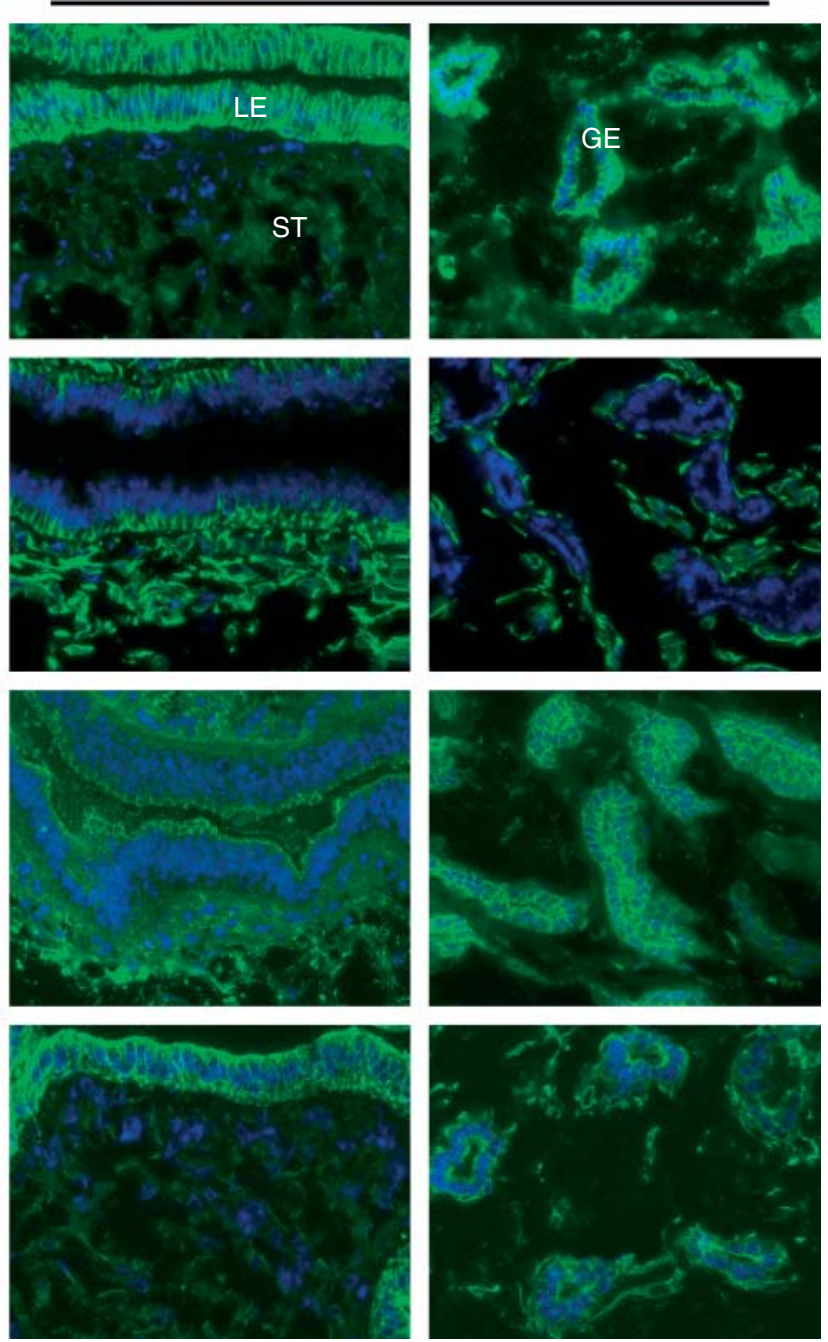

Figure 7 Effects of progesterone on baso-lateral junctional proteins and intermediate cytoskeletal filaments of uterine LE and GE. Immunofluorescence localization of $\alpha_{2} \beta_{1}$ integrin heterodimer, vimentin, E-cadherein, and cytokeratin on day 40 endometria from ovariectomized gilts treated with corn oil or progesterone is shown. The nuclei are stained (blue) with DAPI. Rabbit IgG or mouse IgG applied to endometrial sections from corn oil-treated gilts served as negative controls, and can be observed in Fig. 6 . Width of each field is $540 \mu \mathrm{m}$.

Erikson et al. 2009). In the present study, both LE and GE cells exhibited alterations to their apical domains in response to progesterone. Immunofluorescence staining for DBA lectin showed a nearly complete loss of apical $n$-acetyl-D-glactosamine, the ligand to which it binds, after 40 days of progesterone exposure. There was also downregulation of apical $\alpha_{v}$ integrin. These staining patterns are unique compared with those in other reported functional stages of the uterus. DBA lectin binding is prominent on porcine uterine epithelia throughout GE adenogenesis, and actually increases during the luteal phase of the estrous cycle (Spencer et al. 1992, Sant'Ana et al. 2009). Similarly, $\alpha_{v}$ has high expression at the apical surfaces of LE and GE during the porcine periimplantation period. We hypothesize that these molecules participate in the initial stages of communication between trophectoderm and LE, and high expression is maintained at the apical surface of uterine epithelia in the presence of increasing progesterone levels during the luteal phase and peri-implantation period. However, long-term progesterone exposure eventually decreases expression of these molecules when they are no longer necessary, or may be a physical hindrance to interaction between the uterus and placenta as placentation advances. Mucin-1 has been proposed to have similar roles (Carson et al. 2006), and our own results suggest that apical integrins downregulate at the uterine-placental interface during later stages of pregnancy in pigs (Frank JW, Burghardt RC, Johnson GA, unpublished results).

In contrast to the apical domain, epithelial cells interact with adjacent cells and the underlying basement membrane through their basolateral domains. A complex array of adhesion molecules and junctional 
complexes attach adjacent membrane surfaces and regulate the paracellular transport of molecules for exocrine secretion. In the present study, progesterone did not affect the distribution of E-cadherin, which maintains the lateral attachment of cells that form the epithelial sheet. In addition, there were no clear alterations in tight junctions, which determine cell polarity and control the free passage of substances across the epithelial cell layer. The transmembrane proteins, occludins- 1 and -2 , and claudins- 3 and -4 , were all localized to tight junctions in uteri of both CO-treated pigs and progesterone-treated pigs. It was recently reported that progesterone transiently decreases tight junctions in endometrial LE during early blastocyst development, but then subsequently increases tight junctions during implantation, i.e. the initiation of placentation in sheep (Satterfield et al. 2007). Results of the present study also indicate that tight junction integrity is maintained in both LE and GE of pig uteri during long-term progesterone exposure.

Although adhesion between uterine epithelia was maintained, clear alterations within the basolateral domains were detected in uteri exposed to progesterone. Claudin- $4, \alpha_{2} \beta_{1}$ integrin receptor, and vimentin were all induced at the basolateral surfaces of LE and GE of progesterone-treated pigs. The induction or upregulation of each of these proteins in epithelia has been linked to the cancerous state, and has variously been attributed to increased proliferation and/or changes in cell shape. Both claudins and occludins can be disregulated in a variety of malignancies. The expression of claudins-3 and -4 is reported to be typically low in normal human endometrium, but increases at sites of adenocarcinoma, clear serous papillary, and endometrioid uterine cancers (Pan et al. 2007, Konecny et al. 2008). Of particular interest is the staining pattern that was observed for claudin-4 in normal and cancerous GE. In normal tissue, claudin-4 showed weak to no staining at the apical border of cells, typical of tight junction proteins. However, the GE of adenocarcinomas exhibited strong diffuse punctate staining that covered the entire circumference of the basolateral domain (Pan et al. 2007). This unusual cellular distribution for a tight junction protein was also evident in the LE and GE of progesterone-treated pigs in the present study. The $\alpha_{2} \beta_{1}$ integrin heterodimer is classically a collagen and laminin receptor limited to the basal surface when expressed by epithelia, but is present at contact sites between keratinocytes, suggesting that this integrin can also serve as an intercellular adhesion molecule and/or ligand bridging receptor (Symington et al. 1993). It is noteworthy that $\alpha_{2} \beta_{1}$ expression is enhanced in some proliferating and migrating epithelia, including carcinomas, showing a circumferential cell staining pattern nearly identical to E-cadherin (Zutter \& Santoro 1990, Dahlman et al. 1998). In the present study, there was a dramatic induction of $\alpha_{2} \beta_{1}$ along the entire basolateral surface of LE and GE in response to progesterone. Finally, the LE of long-term progesterone-treated pigs co-expressed the intermediate filament proteins cytokeratin and vimentin. Although cytokeratin was not affected by treatment and showed a typical cellular distribution, vimentin was only present along the basal and lower third of the lateral domains of LE cells. The co-expression of cytokeratin and vimentin is typical of tissue remodeling in mesothelial cells, kidney tubule epithelium regenerating after injury, and cancerous kidney tubule and respiratory epithelia (LaRocca \& Rheinwald 1984, Grone et al. 1987, Kasper et al. 1993). Vimentin is expressed in the epithelia of rat kidney tubules with collapsed lumens and closely packed cells, and is induced in vitro in kidney epithelial cells when growth reaches confluence, suggesting that vimentin synthesis is an epithelial response to disruption of geometric cellto-cell interactions (Grone et al. 1987). As claudin-4, $\alpha_{2} \beta_{1}$ integrin, and vimentin can be regulated in epithelia by cell architecture, cell-matrix interaction, and growth rate, we hypothesize that long-term exposure of the pig endometrium to progesterone stimulates endometrial hyperplasia, which requires limited growth migration and invasion of uterine epithelia. Induction of claudin-4, $\alpha_{2} \beta_{1}$ integrin, and vimentin in LE and GE may reflect tissue remodeling in response to progesterone during pregnancy. It will be of interest to determine the endometrial expression of these proteins during pregnancy in pigs.

Collectively, our results allow us to conclude that progesterone profoundly influences the development and histoarchitecture of porcine uterine epithelia and endothelia, but that hypertrophy and hyperplasia of the GE essential for histotroph production over most of the latter two-thirds of pregnancy require that the uterus is also stimulated by other ovarian and/or placental factors.

\section{Materials and Methods}

\section{Animals, experimental design, and tissue collection}

Sexually mature gilts of similar age, weight, and genetic background were observed daily for estrus (day 0) and exhibited at least two estrous cycles of normal duration (18-21 days) before being used in these studies. All experimental and surgical procedures were in compliance with the Guide for Care and Use of Agricultural Animals in Teaching and Research and approved by the Institutional Animal Care and Use Committee of Texas A\&M University.

To evaluate the effects of long-term progesterone treatment without effects of ovarian or conceptus factors on uterine epithelia, gilts were ovariectomized on day 12 of the estrous cycle and assigned randomly to receive daily injections (i.m.) of either $4 \mathrm{ml}$ CO or $200 \mathrm{mg}$ progesterone (200 $\mathrm{mg}$ in $4 \mathrm{ml} \mathrm{CO}$ ) on days 12-39 post estrus ( $n=4 /$ treatment). All gilts were hysterectomized on day 40 post estrus. Uterine flushings were obtained by introducing and recovering $40 \mathrm{ml}$ sterile Hank's 
balanced salt solution (Sigma Chemical Co.) from the uterine lumen before hysterectomy. The uterine flushings were cleared of cellular debris by centrifugation $\left(3000 \mathrm{~g}\right.$ for $10 \mathrm{~min}$ at $4{ }^{\circ} \mathrm{C}$ ), and frozen at $-80{ }^{\circ} \mathrm{C}$ until analyzed. At hysterectomy, several sections (thickness $\sim 1-1.5 \mathrm{~cm}$ ) from the middle of each uterine horn were placed in fresh $4 \%$ paraformaldehyde fixative for $24 \mathrm{~h}$ and then embedded in Paraplast Plus (Oxford Labware, St Louis, MO, USA). In addition, several $1-1.5 \mathrm{~cm}$ sections of uterine wall from the middle of each horn were snap frozen in Tissue-Tek OCT compound (Miles, Oneata, NY, USA).

\section{Histology and LE and GE morphometry}

Embedded tissues were sectioned $(5 \mu \mathrm{m})$, deparaffinized, and stained with Mayer hematoxylin and eosin for general histomorphological evaluation as described previously (Dunlap et al. 2008). A uterine gland cross section with an open lumen was counted as a gland. Uterine gland numbers were determined for at least six nonsequential uterine cross sections, per gilt, per treatment. Endometrial gland density was defined by counting the number of glands in a $940 \mu \mathrm{m}$ field of view of the endometrium. Height of uterine LE was measured digitally using an Axioplan 2 microscope (Carl Zeiss, Thornwood, NY, USA) interfaced with an Axiocam HR digital camera and Axiovision 4.1 software (Carl Zeiss). Ten measures of LE cell height were taken per section for at least six nonsequential uterine cross sections, per gilt, per treatment. All quantitative measures were subjected to least-squares ANOVA by the general linear models procedures of Statistical Analysis System version 8.1 for Windows (SAS Institute, Cary, NC, USA). Tests of significance were performed by using the appropriate error terms according to the expectation of the mean squares for error.

\section{Western blot analyses}

Uterine flushings were concentrated using Centricon-3 columns (Amicon, Beverly, MA, USA). Protein concentration was determined using the Bradford protein assay (Bio-Rad) with BSA as the standard. Proteins were denatured and separated by $12 \%$ SDS-PAGE, and western blot analyses were performed as described previously (Johnson et al. 1999) using ECL detection (SuperSignal West Pico, Pierce, Rockford, IL, USA) and X-OMAT AR X-ray film (Kodak). Immunoreactive CTSB protein was detected using the rabbit anti-rat CTSB polyclonal IgG $(2.5 \mu \mathrm{g} / \mathrm{ml}$, Catalog number 06-480; Upstate, Lake Placid, NY, USA). Immunoreactive ACP5 protein was detected using affinity-purified rabbit anti-ACP5 $(2.5 \mu \mathrm{g} / \mathrm{ml}$; Ellenberger et al. 2008). Multiple exposures of each western blot were performed to ensure linearity of chemiluminescent signals.

\section{Immunofluorescence staining and vascular morphometry}

Primary antibodies used for immunostaining included rabbit anti- $\alpha_{v}$ (\#AB1930) integrin subunit and mouse anti- $\alpha_{2} \beta_{1}$ (\#MAB 1998Z) integrin heterodimer from Chemicon (Temecula, CA, USA); mouse anti-cytokeratin (\#6909), mouse anti-vimentin $(\# \mathrm{v}-6630)$, normal rabbit IgG (\#15006), and normal mouse
IgG (\#15381) from Sigma-Aldrich; mouse anti-E-cadherin (\#610182) from BD Biosciences (San Jose, CA, USA); rabbit anti-ZO-1 (\#61-7300), rabbit anti-ZO-2 (\#71-1400), rabbit anti-claudin 3 (\#34-1700), and rabbit anti-claudin 4 (\#36-4800) from Zymed Laboratories (San Francisco, CA, USA); and rabbit anti-von Willebrand factor (vWF) (\#A0082) from Dako (Carpinteria, CA, USA). Secondary antibodies used for immunostaining included goat anti-rabbit IgG Alexa 488 and goat anti-mouse IgG Alexa 488.

Proteins were localized in frozen uterine tissue sections by immunofluorescence staining as previously described (Johnson et al. 1999). Sections were fixed and permeabilized in $-20{ }^{\circ} \mathrm{C}$ methanol, washed in PBS containing $0.3 \% \mathrm{vol} / \mathrm{vol}$ Tween-20 (immunofluorescence rinse solution), blocked in $10 \%$ normal goat serum, and incubated overnight at $4{ }^{\circ} \mathrm{C}$ with primary antibody at a dilution optimized for each antibody. Immunoreactive proteins were detected using an appropriate Alexa Fluor 488-conjugated secondary antibody for $1 \mathrm{~h}$ at room temperature at a dilution of 1:250. Slides were overlaid with a coverslip and Prolong antifade mounting reagent containing the nuclear counterstain DAPI (Invitrogen, Molecular Probes, Eugene, OR, USA).

Estimation of differences in vasculature between CO- and progesterone-treated animals was evaluated by quantifying vWF staining in nonoverlapping fields of endometrium captured with a $\times 10$ planapochromat lens $(0.45 \mathrm{NA})$ from areas adjacent to uterine LE (shallow endometrium) through to the myometrium (deep endometrium). Anti-vWF IgG reacts with VWF factor present in endothelial cells and in the cytoplasm of megakaryocytes. Digital images $(870 \times 690 \mu \mathrm{m})$ were analyzed using Metamorph software by uniformly thresholding images to identify vWF-stained endothelium, and the area within each image occupied by vWF fluorescence was determined. At least, three sections from four animals were completely imaged for each treatment, and data were analyzed by two-way ANOVA and Bonferroni post hoc test at $P<0.05$.

\section{Fluorescence DBA lectin staining}

DBA lectin staining, as an index of glycocalyx development on uterine LE and GE, was localized in paraffin-embedded porcine uterine tissues using an FITC-conjugated lectin from Dolichos biflorus (\#L9142-1MG, Sigma). Sections $(5 \mu \mathrm{m})$ of the entire uterine horn from $\mathrm{CO}$ - and progesterone-treated gilts were affixed to Superfrost Plus slides (Fisher Scientific, Pittsburgh, PA, USA). For fluorescence localization, sections were deparaffinized in xylene and rehydrated to water through a graded alcohol series. Sections were then incubated with DBA lectin-FITC conjugate in immunofluorescence rinse solution and incubated overnight at $4{ }^{\circ} \mathrm{C}$. Sections were lightly stained with hematoxylin, and overlaid with a coverslip and Prolong antifade mounting reagent containing the nuclear counterstain DAPI (Invitrogen).

\section{Photomicrography}

Digital fluorescence images were evaluated using an Axioplan 2 microscope (Carl Zeiss) interfaced with an Axioplan HR digital camera and Axiovision 4.4 software. Individual 
fluorophore and DAPI images were recorded sequentially and evaluated as overlay images or as single channel images for quantification of fluorescence. Photographic plates were assembled using Adobe Photoshop CS2 (version 9.0, Adobe Systems Inc.).

\section{Declaration of interest}

The authors declare that there is no conflict of interest that could be perceived as prejudicing the impartiality of the research reported.

\section{Funding}

This project was supported by National Research Initiative Competitive Grant No. 2006-35203-17199 from the USDA National Institute of Food and Agriculture.

\section{Acknowledgements}

The authors thank Dr Rola Barhoumi of the College of Veterinary Medicine and Biomedical Sciences Image Analysis Laboratory for performing quantification and statistical analysis of von Willebrand factor staining.

\section{References}

Ace CI \& Okulicz WC 2004 Microarray profiling of progesteroneregulated endometrial genes during the rhesus monkey secretory phase. Reproductive Biology and Endocrinology 2 54-62. (doi:10. 1186/1477-7827-2-54)

Bartol FF, Wiley AA, Spencer TE, Vallet JL \& Christenson RK 1993 Early uterine development in pigs. Journal of Reproduction and Fertility. Supplement 48 99-116.

Bartol FF, Wiley AA \& Bagness CA 2006 Uterine development and endometrial programming. Society of Reproduction and Fertility Supplement 62 113-130.

Basha SM, Bazer FW, Geisert RD \& Roberts RM 1980 Progesteroneinduced uterine secretions in pigs. Recovery from pseudopregnant and unilaterally pregnant gilts. Journal of Animal Science 50 113-123.

Bowen JA, Bazer FW \& Burghardt RC 1996 Spatial and temporal analyses of integrin and Muc-1 expression in porcine uterine epithelium and trophectoderm in vivo. Biology of Reproduction 55 1098-1106. (doi:10.1095/biolreprod55.5.1098)

Brenner RM \& Slayden OD 1994 Cyclic changes in the primate oviduct and endometrium. In The Physiology of Reproduction, pp 541-569. Eds E Knobil \& JO Neill. New York: Raven Press.

Carson DD, Julian J, Lessey BA, Prakobphol A \& Fisher SJ 2006 MUC1 is a scaffold for selectin ligands in the human uterus. Frontiers in Bioscience 11 2903-2908. (doi:10.2741/2018)

Carter F, Forde N, Duffy P, Wade M, Crowe MA, Evans AC, Kenny DA, Roche JF \& Longergan P 2008 Effect of increasing progesterone concentration from day 3 of pregnancy on subsequent embryo survival and development in beef heifers. Reproduction, Fertility, and Development 20 368-375. (doi:10.1071/RD07204)

Chilton BS, Mani SK \& Bullock DW 1988 Servomechanism of prolactin and progesterone in regulating uterine gene expression. Molecular Endocrinology 2 1169-1175. (doi:10.1210/mend-2-12-1169)

Dahlman T, Grimelius L, Wallin G, Rubin K \& Westermark K 1998 Integrins in thyroid tissue: upregulation of $\alpha_{2} \beta_{1}$ in anaplastic thyroid carcinoma. European Journal of Endocrinology 138 104-112. (doi:10.1530/eje.0. 1380104)

Dantzer V 1985 Electron microscopy of the initial stages of placentation in the pig. Anatomy and Embryology 172 281-293. (doi:10.1007/ BF00318976)
Davies J \& Hoffman LH 1975 Studies on the progestational endometrium of the rabbit. II. Electron microscopy, day 0 to day 13 of gonadotrophininduced pseudopregnancy. American Journal of Anatomy 142 335-365. (doi:10.1002/aja.1001420305)

Dunlap KA, Burghardt RC, Erikson DW, Reed KM, White FJ, Farmer JL, Spencer TE, Magness RR, Bazer FW, Bayless KJ et al. 2008 Progesterone and placentation increase uterine glandular and stromal secreted phosphoprotein 1 (osteopontin) that may function for histotrophic and hematotrophic support of ovine pregnancy. Biology of Reproduction $\mathbf{7 9}$ 983-990. (doi:10.1095/biolreprod.108.071068)

Ellenberger C, Wilsher S, Allen WR, Hoffmann C, Kolling M, Bazer FW, Klug J, Schoon D \& Schoon HA 2008 Immunolocalisation of the uterine secretory proteins uterocalin, uteroferrin and uteroglobin in the mare's uterus and placenta throughout pregnancy. Theriogenology 70 746-757. (doi:10.1016/j.theriogenology.2008.04.050)

Erikson DW, Burghardt RC, Bayless KJ \& Johnson GA 2009 Secreted phosphoprotein 1 (SPP1, osteopontin) binds to integrin $\alpha_{v} \beta_{6}$ on porcine trophectoerm cells and integrin $\alpha_{v} \beta_{3}$ on uterine luminal epithelial cells, and promotes torphectoderm cell adhesion and migration. Biology of Reproduction 81 814-825. (doi:10.1095/biolreprod.109.078600)

Garlow JE, Ka H, Johnson GA, Burghardt RC, Jaeger LA \& Bazer FW 2002 Analysis of osteopontin at the maternal-placental interface in pigs. Biology of Reproduction 66 718-725. (doi:10.1095/biolreprod66.3.718)

Geisert RD, Renegar RH, Thatcher WW, Roberts RM \& Bazer FW 1982a Establishment of pregnancy in the pig. I. Interrelationships between preimplantation development of the pig blastocyst and uterine endometrial secretions. Biology of Reproduction 27 925-939. (doi:10. 1095/biolreprod27.4.925)

Geisert RD, Thatcher WW, Roberts RM \& Bazer FW 1982b Establishment of pregnancy in the pig. III. Endometrial secretory response to estradiol valerate administered on day 11 of the estrous cycle. Biology of Reproduction 27 957-965. (doi:10.1095/biolreprod27.4.957)

Geisert RD, Fox TC, Morgan GL, Wells ME, Welleman RP \& Zavy MT 1991 Survival of bovine embryos transferred to progesterone-treated asynchronous recipients. Journal of Reproduction and Fertility 92 475-482. (doi:10.1530/jrf.0.0920475)

Geisert RD, Pratt TN, Bazer FW, Mayes JS \& Watson GH 1994 Immunocytochemical localization and changes in endometrial progestin receptor protein during the porcine oestrous cycle and early pregnancy. Reproduction, Fertility, and Development 6 749-760. (doi:10.1071/ RD9940749)

Geisert RD, Dixon MJ, Pratt T, Schmitt RAM, Lessley BA \& McCann JP 1995 Isolation and characterization of a 30-kDA endometrial glycoprotein synthesized during the estrous cycle and early pregnancy of the pig. Biology of Reproduction 53 1038-1050. (doi:10.1095/biolreprod53. 5.1038)

Gray CA, Bartol FF, Tarleton BJ, Wiley AA, Johnson GA, Bazer FW \& Spencer TE 2001 Minireview: developmental biology of uterine glands. Biology of Reproduction 65 1311-1323. (doi:10.1095/biolreprod65.5. 1311)

Gray CA, Abbey CA, Beremand PD, Choi Y, Farmer JL, Adelson DL, Thomas TL, Bazer FW \& Spencer TE 2006 Identification of endometrial genes regulated by early pregnancy, progesterone, and interferon tau in the ovine uterus. Biology of Reproduction 74 383-394. (doi:10.1095/ biolreprod.105.046656)

Grone HJ, Weber K, Grone E, Helmchen U \& Osborn M 1987 Coexpression of keratin and vimentin in damaged and regenerating tubular epithelia of the kidney. American Journal of Pathology 129 1-8.

Hempstock J, Cindrova-Davies T, Jauniaux E \& Burton GJ 2004 Endometrial glands as a source of nutrients, growth factors and cytokines during the first trimester of human pregnancy: a morphological and immunohistochemical study. Reproductive Biology and Endocrinology 2 58-72. (doi:10.1186/1477-7827-2-58)

Jeong JW, Lee KY, White LD, Hilsenbeck SG, Lydon JP \& DeMayo FJ 2005 Identification of murine uterine genes regulated in a ligan-dependent manner by the progesterone receptor. Endocrinology 146 3490-3505. (doi:10.1210/en.2005-0016)

Johnson GA, Burghardt RC, Spencer TE, Newton GR \& Bazer FW 1999 Ovine osteopontin: II. Osteopontin and $\alpha_{v} \beta_{3}$ integrin expression in the uterus and conceptus during the peri-implantation period. Biology of Reproduction 61 892-899. (doi:10.1095/biolreprod61.4.892) 
Johnson GA, Bazer FW, Burghardt RC, Spencer TE \& Bayless KJ 2009 Conceptus-uterus interactions in pigs: endometrial gene expression in response to estrogens and interferons from conceptuses. Society of Reproduction and Fertility Supplement 66 321-332.

Joyce MM, Burghardt JR, Burghardt RC, Hooper RN, Bazer FW \& Johnson GA 2008 Uterine MHC class I molecules and beta 2 -microglobulin are regulated by progesterone and conceptus interferons during pig pregnancy. Journal of Immunology 181 2494-2505.

Ka H, Al-Ramadan S, Erikson DW, Johnson GA, Burghardt RC, Spencer TE, Jaeger LA \& Bazer FW 2007 Regulation of fibroblast growth factor 7 expression in the pig uterine endometrium by progesterone and estradiol. Biology of Reproduction 77 172-180. (doi:10.1095/biolreprod.106. 056309)

Kasper M, Rudolf T, Hahn R, Peterson I \& Muller M 1993 Immuno- and lectin histochemistry of piehtlial subtypes and their changes in a radiation-induced lung fibrosis model of the mini pig. Histochemistry 100 367-377. (doi:10.1007/BF00268935)

Knight JW, Bazer FW \& Wallace HD 1973 Hormonal regulation of porcine uterine protein secretion. Journal of Animal Science 36 546-553.

Knight JW, Bazer FW \& Wallace HD 1974a Effect of progesterone induced increase in uterine secretory activity of development of the porcine conceptus. Journal of Animal Science 39 743-746.

Knight JW, Bazer FW, Wallace HD \& Wilcox CJ 1974b Dose-response relationships between exogenous progesterone and estradiol and porcine uterine protein secretions. Journal of Animal Science 39 747-751.

Knight JW, Bazer FW, Thatcher WW, Franke DE \& Wallace HD 1977 Conceptus development in intact and unilaterally hysterectomizedovariectomized gilts: interrelations among hormonal statu, placental development, fetal fluids and fetal growth. Journal of Animal Science $\mathbf{4 4}$ 620-637.

Konecny GE, Agarwal R, Keeney GA, Winterhoff B, Jones MB, Mariani A, Riehle D, Neuper C, Dowdy SC, Wang HJ et al. 2008 Claudin-3 and claudin-4 expression in serous papillary, clear-cell and endometrioid endometrial cancer. Gynecologic Oncology 109 263-269. (doi:10. 1016/j.ygyno.2008.01.024)

LaRocca PJ \& Rheinwald JG 1984 Coexpression of simple epithelial keratins and vimentin by human mesothelium and mesotheliona in vivo and in culture. Cancer Research 44 2991-2999.

Murray MK 1992 The effect of estrogen and progesterone on structural changes in the uterine glandular epithelium of the oavriectomized sheep. Biology of Reproduction 47 408-417. (doi:10.1095/ biolreprod47.3.408)

Pan XY, Wang B, Che YC, Weng ZP, Dai HY \& Peng W 2007 Expression of claudin-3 and claudin-4 in normal, hyperplastic and malignant endometrial tissue. International Journal of Gynecological Cancer 17 233-241. (doi:10.1111/j.1525-1438.2006.00748.x)

Perry JS \& Crombie PR 1982 Ultrastructure of the uterine glands of the pig. Journal of Anatomy 134 339-350.

Roberts RM \& Bazer FW 1988 The functions of uterine secretions. Journal of Reproduction and Fertility 82 875-892. (doi:10.1530/jrf.0.0820875)

Ross JW, Malayer JR, Ritchey JW \& Geisert RD 2003 Involvement of the interleukin-1 $\beta$ system in porcine trophoblastic elongation and at the fetal-maternal interface during peri-implantation development. Biology of Reproduction 69 1251-1259. (doi:10.1095/biolreprod.103. 015842)

Sant'Ana FJF, Nascimento EF, Andres laube PF, Gimeno EJ \& Barbeito CG 2009 Lectin-binding sites on the normal and pathologic uterus of sows. Reproduction in Domestic Animals 44 889-893. (doi:10.1111/j.14390531.2008.01107.x)

Satterfield MC, Bazer FW \& Spencer TE 2006 Progesterone regulation of preimplantation conceptus growth and galectin 15 (LGALS15) in the ovine uterus. Biology of Reproduction 75 289-296. (doi:10.1095/ biolreprod.106.052944)
Satterfield MC, Dunlap KA, Hayashi H, Burghardt RC, Spencer TE \& Bazer FW 2007 Tight and adherens junctions in the ovine uterus: differential regulation by pregnancy and progesterone. Endocrinology 148 3922-3931. (doi:10.1210/en.2007-0321)

Schlosnagle DC, Bazer FW, Tsibris JCM \& Roberts RM 1974 An ironcontaining phosphatase induced by progesterone in the uterine fluids of pigs. Journal of Biological Chemistry 249 7574-7579.

Sinowatz F \& Friess AE 1983 Uterine glands of the pig during pregnancy. An ultrastructural and cytochemical study. Anatomy and Embryology 166 121-134. (doi:10.1007/BF00317948)

Song G, Dunlap KA, Kim J, Bailey DW, Spencer TE, Burghardt RC, Johnson GA \& Bazer FW 2009 Stanniocalcin 1 is a luminal epithelial marker for implantation in pigs regulated by progesterone and estrogen. Endocrinology 150 936-945. (doi:10.1210/en.2008-1026)

Song G, Bailey DW, Dunlap KA, Burghardt RC, Spencer TE, Bazer FW \& Johnson GA 2010 Cathepsin B, cathepsin L and cystatin C in the procine uterus and placenta: potential roles in endometrial/placental remodeling and in fluid-phase transport of proteins secreted by uterine epithelia across placental areola end neonatal gut. Biology of Reproduction 82 854-864. (doi:10.1095/biolreprod.109.080929)

Spencer TE, Gray CA, Johnson GA, Taylor KM, Gertler A, Gootwine E, Ott TL \& Bazer FW 1999 Effects of recombinant ovine interferon tau, placental lactogen, and growth hormone on the ovine uterue. Biology of Reproduction 61 1409-1418. (doi:10. 1095/biolreprod61.6.1409)

Spencer TE, Wiley AA \& Bartol FF 1992 Lectin binding sites as markers of neonatal porcine uterine development. Journal of Histochemistry and Cytochemistry 40 1937-1942.

Spencer TE, Johnson GA, Burghardt RC \& Bazer FW 2004 Progesterone and placental hormone actions on the uterus: insights from domestic animals. Biology of Reproduction 71 2-10. (doi:10.1095/biolreprod. 103.024133)

Symington BE, Takada Y \& Carter WG 1993 Interaction of integrins alpha 3 beta 1 and alpha 2 beta 1 : potential role in keratinocyte intercellular adhesion. Journal of Cell Biology 120 525-535. (doi:10.1083/jcb.120.2.523)

Verhage HG, Murray MK, Boomsma RA, Rehfeldt PA \& Jaffe RC 1984 The post ovulatory cat oviduct and uterus: correlation of morphological features with progesterone receptor levels. Anatomical Record 208 521-531. (doi:10.1002/ar.1092080408)

Welter H, Wollenhaupt K, Tiemann U \& Einspanier R 2003 Regulation of the VEGF-system in the endometrium during steroid-replacement and rearly pregnancy of pigs. Experimental and Clinical Endocrinology 111 33-40. (doi:10.1055/s-2003-37498)

Welter H, Wollenhaupt K \& Einspanier R 2004 Developmental and hormonal regulated gene expression of fibroblast growth factor 2 (FGF-2) and its receptors in porcine endometrium. Steroid Biochemistry and Molecular Biology 88 295-304. (doi:10.1016/j.jsbmb.2003.12.011)

Young KH, Kraeling RR \& Bazer FW 1990 Effect of pregnancy and exogenous ovarian steroids on endometrial prolactin receptor ontogeny and uterine secretory response in pigs. Biology of Reproduction 43 592-599. (doi:10.1095/biolreprod43.4.592)

Yun SM, Choi KC, Kim IH, An BS, Lee GS, Hong EJ, Oh GT \& Jeung EB 2004 Dominant expression of porcine Calbindin-D9k in the uterus during a luteal phase. Molecular Reproduction and Development 67 251-256. (doi:10.1002/mrd.20019)

Zutter MM \& Santoro SA 1990 Widespread histologic distribution of the alpha 2 beta 1 integrin cell-surface collagen receptor. American Journal of Pathology 137 113-120.

Received 5 April 2010

First decision 17 May 2010

Revised manuscript received 25 June 2010

Accepted 15 July 2010 